\title{
A variação na concordância de número no sintagma nominal no português rural da serra fluminense: deriva ou contato?
}

Jaqueline de Moraes Thurler Dália ${ }^{a}$

Dante Lucchesi ${ }^{b}$

\begin{abstract}
Resumo
O artigo apresenta uma análise sociolinguística em tempo aparente da variação na concordância de número no Sintagma Nominal (SN) no português rural da Região Serrana do estado do Rio de Janeiro. Observou-se a aplicação ou não da regra no SN como um todo, no que se denominou abordagem sintagmática ou não-atomística. A análise variacionista baseou-se em uma amostra de fala vernácula colhida na zona rural do município de Nova Friburgo, com 35 informantes de duas gerações, distribuídos pelos dois sexos. Os dados de fala foram submetidos ao processamento quantitativo de cálculo multivariado, com a utilização do programa GoldVarb, para identificar os condicionamentos sociais do fenômeno variável. Assumiu-se que a variação na concordância nominal de número é o resultado de uma mudança induzida pelo contato entre línguas ocorrido no passado, considerando a história sociolinguística do Brasil como um todo
\end{abstract}

Recebido em: 27/06/2020 Aceito em: 13/10/2020

\footnotetext{
a Professora de Língua Portuguesa do Instituto Federal Fluminense, Cambuci, RJ, Brasil.

E-mail: jaquelinethurlerdalia@gmail.com

b Universidade Federal Fluminense, Instituto de Letras, Departamento de Letras Clássicas e Vernáculas,

Niterói, RJ, Brasil. E-mail: dante.lucchesi@gmail.com
}

\section{Como citar:}

Dália, J. M. T.; Dante Luccchesi, D. A variação na concordância de número no sintagma nominal no português rural da serra fluminense: deriva ou contato? Gragoatá, Niterói, v.26, n.54, p. 217-251, 2021. 
e, particularmente, o multilinguismo presente na história da região, que congregou colonos suíços e alemães, além de colonos portugueses e brasileiros e africanos escravizados. Portanto, a hipótese que norteou toda a análise foi a de que o mecanismo da concordância nominal teria se erodido no passado em função do contato linguístico e, atualmente, estaria se recompondo em função do nivelamento linguístico que caracteriza o português popular desde meados do século XX, no contexto da polarização sociolinguística do Brasil. Os resultados empíricos comprovaram que o contato entre línguas atuou fortemente na formação das variedades populares do português do Brasil, afetando principalmente os mecanismos gramaticais que não têm valor informacional.

Palavras-chave: Concordância nominal. Português rural. Variação linguística. Contato entre línguas. Deriva.

\section{Introdução}

Neste artigo, são apresentados os resultados de uma análise da variação na concordância de número no Sintagma Nominal que ocorre no vernáculo de famílias rurais da Região Serrana do Estado do Rio de Janeiro, utilizando o instrumental teórico e metodológico da Sociolinguística Variacionista (WEINREICH; LABOV; HERZOG, 2006[1968]; LABOV, 2008[1972], 1994, 2001a, 2001b, 2010). A variação na concordância nominal de número é um dos fenômenos que se coloca centralmente no debate sobre a participação do contato entre línguas na formação das variedades populares do português do Brasil (NARO; SCHERRE, 2007; LUCCHESI, 2012a, entre outros). Assume-se aqui que esse fenômeno tem origem na erosão morfológica decorrente da aquisição imperfeita do português como segunda língua por indígenas, africanos e povos falantes de outros idiomas que colonizaram a região, no que se definiu como transmissão linguística irregular (LUCCHESI; BAXTER, 2009; LUCCHESI, 2008, 2013, 2015), e que se perpetuou, através do tempo, devido ao acesso restrito à 
educação formal por grande parte da população. Todavia, desde meados do século XX, estaria ocorrendo um aumento do uso da regra de concordância, em função da ampliação do sistema público de educação, da influência dos meios de comunicação de massa e do deslocamento sazonal dos indivíduos por razões de trabalho, em um processo de nivelamento linguístico que caracteriza o estágio atual da polarização sociolinguística do Brasil (LUCCHESI, 2015).

A análise se baseou em uma amostra de fala vernácula colhida junto às comunidades da região, com foco em duas gerações, que apresentam padrões bem distintos de escolarização. A primeira foi composta por 14 trabalhadores rurais entre 35 e 55 anos que, em sua maioria, só tiveram oportunidade de cursar até o $1^{\circ}$ segmento do Ensino Fundamental, ou seja, muitos deles abandonaram a escola quando foram apenas alfabetizados. A segunda foi constituída por 21 jovens, filhos desses trabalhadores, entre 14 e 19 anos, estudantes do Ensino Médio, que veem e almejam hoje a concreta possibilidade de verticalização dos estudos. Portanto, a amostra constituída reuniu 35 informantes, dos quais 16 são homens e 19 mulheres, nascidos nesses bairros. O recorte do campo de investigação foi realizado com base na teoria da Sociologia Rural (CANDIDO, 2010; COMERFORD, 2005; FRAZÃO, 2015; OLIVEIRA, 2011).

Os informantes foram selecionados de acordo com sua distribuição pelo território rural do $3^{\circ}$ Distrito de Nova Friburgo, na Região Serrana do Estado do Rio de Janeiro. O município é conhecido pela colonização suíça e alemã, porém estudos históricos têm revelado a presença expressiva de colonos portugueses e de africanos escravizados. Essa composição pluriétnica e plurilíngue constitui, em princípio, um contexto favorável a mudanças induzidas pelo contato (WINFORD, 2003). Contudo, o desenvolvimento socioeconômico da região teria inibido mudanças mais radicais no vernáculo da região.

Foi realizada uma análise em tempo aparente na qual se buscou identificar os fatores sociais que condicionam o processo de variação, e testou-se a hipótese de que estaria em curso um processo de mudança em progresso no sentido do incremento do uso da regra da concordância de número no Sintagma Nominal (SN) na comunidade. Foi observada a aplicação ou não da regra no SN como um todo. 
Este artigo está estruturado da seguinte maneira: a primeira seção traça um breve panorama histórico da comunidade, que serviu de base para a formulação da hipótese que orienta a análise; a segunda seção faz uma breve resenha dos estudos sociolinguísticos sobre a variação na concordância nominal, considerando a questão do contato entre línguas; e, na terceira seção, são apresentados os resultados da análise quantitativa do encaixamento do fenômeno variável no contexto sociocultural da comunidade de fala. Na conclusão, a hipótese acerca da origem do fenômeno variável é confrontada com os resultados apresentados.

\section{O contexto sócio-histórico da comunidade}

A posição teórica aqui adotada é a de que as situações de contato massivo entre línguas conduzem historicamente à simplificação morfológica das variedades linguísticas que se formam ou passam por essas situações (WINFORD, 2003; MCWHORTER, 2007; LUCCHESI, 2008, 2012a, 2013; TRUDGILL, 2001, 2009; 2010). Os casos mais radicais de contato dão ensejo a uma língua qualitativamente distinta das línguas envolvidas na sua formação, uma língua pidgin ou crioula. No Brasil, não houve um processo duradouro e representativo de pidginização e/ou crioulização do português, mas um processo de transmissão linguística irregular de tipo leve, cujo efeito mais notável é o amplo processo de variação no emprego de mecanismos morfossintáticos sem carga informacional (como as regras de concordância), que se observa principalmente nas variedades populares do português brasileiro (LUCCHESI, 2009; 2012b; 2015; 2019a, 2019b). Assume-se aqui que a formação histórica do português rural de Nova Friburgo também foi marcada por tal processo de transmissão irregular, já que o contato entre línguas no município foi intenso até a segunda metade do século XIX.

O território onde hoje se encontra o município foi, no início do século XIX, desmembrado da cidade de Cantagalo. Toda essa região, em finais do século XVIII, configurava-se como potencial zona de contrabando de ouro e como refúgio para tribos indígenas e quilombolas. Nesse cenário, o Governo Real buscou medidas para extinguir o garimpo e o tráfico e retomar a exploração do território. Como os resultados não 
foram bons, em 1803, a Coroa distribuiu sesmarias para a produção de café, o que aumentou o número de colonos lusomineiros (LISBOA, 2003, p.81; BON, 2004, p.85). Assim, a lógica observada na Serra Fluminense naquele momento não era diferente da cultura de imigração portuguesa e escravista do restante do país, caracterizada, em termos sociolinguísticos, por um contato linguístico massivo não suficientemente radical a ponto de produzir variedades pidginizadas ou crioulizadas do português (LUCCHESI, 2009, 2015, 2019a, 2019b).

Como aquela área ainda carecia de ocupação, colocouse em prática um projeto de colonização de povoamento, no qual, em 1820, 261 famílias de origem suíça foram implantadas na recém-criada Vila de Nova Friburgo (MAYER, 2003, p.2630). Segundo Nicoulin (1995, p.111), os helvéticos e apátridas que moravam na Suíça somariam 2.018 passageiros que seriam transportados para cá, dos quais $72 \%$ dominavam o francês e $28 \%$ o alemão, porém as más condições da viagem e as moléstias adquiridas no percurso fizeram com que esse contingente não chegasse intacto aqui. No Brasil, as péssimas circunstâncias de moradia e de terreno para cultivo fizeram com que esses colonos se espraiassem para além do Centro da Vila, ampliando, assim, as possibilidades de contato e transmissão linguística irregular. Em 1824, 342 imigrantes alemães chegaram à cidade, ocupando, principalmente, os lotes coloniais centrais abandonados pelos suíços (BON, 2004, p. 115). E, em 1833, mais 54 imigrantes suíços se integraram nesse processo, sem que seus destinos fossem diferentes dos anteriores, o que também os motivou a continuar seu movimento migratório para as regiões adjacentes (BON, 2004, p. 129).

Embora houvesse indígenas nas imediações da Vila quando os colonos chegaram, o estabelecimento do contato entre os dois grupos foi logo cerceado por uma ordem expedida no Rio de Janeiro, que determinava o afastamento das tribos. Relatos de anos anteriores dão conta de que os poucos índios ali remanescentes se vestiam como portugueses e estavam "já parcialmente aculturados" (BON, 2004, p.87). Daí se pode deduzir que, de alguma forma, o português já devia ter sido adquirido de forma irregular pelos povos nativos, mas não ainda pelos suíços. Já no que se refere à interação entre os 
${ }^{1}$ Na década de 1840 , suíços e alemães foram responsáveis por mais da metade da compra de escravos na Vila (MARRETTO, 2018, p.63).

${ }^{2}$ Em 1850, Antonio Clemente Pinto, maior escravista da Região, possuía 75\% de escravos africanos e apenas $26 \%$ de crioulos (MARRETTO, 2018, p. 94).

${ }^{3}$ Há inúmeros registros indicando que vários imigrantes não dominavam e nunca viriam a dominar a Língua Portuguesa, o que provocou vários embaraços e dificuldades sociais.

4 Termo corrente em publicações do século XIX que tratavam de atividades econômicas nos diferentes municípios da província do Rio de Janeiro, como o Almanak Laemert.

${ }^{5}$ Segundo Frazão (2020, p.69-70), o CENSO de 1872 aponta que as duas freguesias (São João Batista e Sebastiana) circunvizinhas ao que se conhece hoje como $3^{\circ}$ Distrito mantinham uma população percentual total de $7,3 \%$ a $9,5 \%$ de portugueses. Quando analisados apenas o CENSO de imigrantes, observase que o número europeus e os homens e mulheres dos mais diversos povos africanos aqui subjugados, percebe-se um processo diverso.

Em um primeiro momento, os suíços se desconfortaram com a escravidão (JOYE, 2005 [1819], s/p). Todavia, alguns dos imigrantes, logo que se estabeleceram financeiramente, inseriram-se na lógica escravista, principalmente aqueles que rumaram para terras limítrofes à Vila, onde se podia produzir café (MARRETTO, 2018, p. 97-102). Assim, repetiram o sistema senhorial ${ }^{1}$ e, em consequência, estreitaram seu convívio com quem já havia adquirido ou estava adquirindo de forma irregular o português ${ }^{2}$ e, em contrapartida, também ofereceram aos cativos o contato com um outro português que também seria adquirido por eles de forma irregular ${ }^{3}$. Registra-se com isso, na Vila de Nova Friburgo e região, uma situação propícia para a alteração da estrutura das variedades de português que ali se formavam, tanto por parte do grupo de suíços e alemães quanto por parte do grupo de origem africana.

Vale lembrar que a única variedade do português brasileiro para a qual há fortes evidências de um possível passado crioulo se encontra no sul da Bahia, em Helvécia, tendo-se originado em grandes plantações de café que colonos suíços e alemães implantaram na localidade no século XIX e que empregavam largamente a mão de obra de escravos africanos (FERREIRA, 1984; BAXTER; LUCCHESI, 1999).

No $3^{\circ}$ Distrito friburguense, o contato com colonos suíços e alemães parece ter sido minimizado uma vez que os registros indicam uma presença reduzida desse grupo na localidade. Desde cedo, configurou-se ali uma região composta por fazendas de criar ${ }^{4}$ e de abastecimento de gêneros alimentícios (FRAZÃO, 2020, p. 63), o que resultou, também, na presença de mão de obra escrava. Novamente, não se tem registro de que nesse território tenha havido uma língua crioula ou pidgin, mas é muito provável que a transmissão linguística irregular, ao menos, de tipo leve, tenha acontecido. Outro fato que pode ter contribuído para a não ocorrência de um contato linguístico mais radical foi a sucessiva leva de portugueses que continuaram se instalando na região ${ }^{5}$.

De qualquer forma, o grau de desenvolvimento humano que caracteriza a localidade, se comparado com a maioria das demais regiões do país, sobretudo o Norte e o Nordeste, teria sido determinante para fazer com que as alterações 
de portugueses é bastante significativo, girando entre

$54,6 \%$ e $60,4 \%$. Tais percentuais refletem o estímulo à imigração lusa observada, principalmente, na corte (LUCCHESI, 2015). produzidas pelo contato linguístico não tenham logrado um efeito mais profundo. Contudo, um outro aspecto importante para a compreensão da formação do vernáculo desses bairros é o fato de a comunidade só ter tido acesso a uma escola de $2^{\circ}$ Segmento do Ensino Fundamental em 1994 e, de Ensino Médio, apenas em 1998. Isso a difere do Centro da Cidade, que viu suas escolas se tornarem referência e atraírem os filhos da elite, não só do Estado, já entre meados do século XIX e XX (FERREIRA, 2019, p. 68).

Ainda hoje, o $3^{\circ}$ Distrito é uma importante zona de abastecimento do Rio de Janeiro, formada por minifúndios com mão de obra basicamente familiar. Seu território conta com 12 bairros, dos quais 7 podem ser considerados rurais (FRAZÃO, 2015; OLIVEIRA, 2011). Percebe-se que, na divisão do trabalho agrícola, embora toda a família se comprometa com ele, e na organização da vida cotidiana, há papéis bem distintos entre homens e mulheres. Esse arranjo histórico e social pode ter influência direta na variação diagenérica, como se verá adiante.

\section{A concordância de número no português brasileiro e o contato entre línguas}

A concordância verbal e nominal estão no centro do debate sobre o papel desempenhado pelo contato entre línguas na formação histórica do português brasileiro (PB) (LUCCHESI, 2012a). Naro e Scherre (2007) defendem que a variação no PB é o resultado de uma deriva secular que remonta à formação do português europeu (PE) e tomaram como evidência crucial o fato de a variação na concordância nominal e verbal também ocorrerem em Portugal. Contudo, análises variacionistas mais recentes têm demonstrado que a aplicação das regras de concordância nominal e verbal no PE é praticamente categórica (BRANDÃO; VIEIRA, 2012; VIEIRA; BAZENGA, 2013), o que suporta a seguinte generalização: "a ausência de marcas de concordância é quantitativamente irrelevante no português europeu e tipologicamente limitada - o português europeu caracteriza-se globalmente pela reiteração das marcas morfológicas de concordância" (MOTA et al., 2012, p. 166). Especificamente em relação à concordância nominal de número, Brandão (2013), em um importante estudo variacionista do fenômeno que contrasta variedades do PE, do 
PB e do português de São Tomé e Príncipe (STP), na África, revelou que, ao contrário do que se observa no PB e no STP, a aplicação da regra de concordância nominal de número no PE é praticamente categórica, com uma frequência de geral de aplicação da regra de 99,89\% encontrada em amostras de fala urbana, constituídas, a partir de 2008, na região metropolitana de Lisboa e do Funchal na Ilha da Madeira, nas quais foram elicitadas quase 7.000 ocorrências de SNs pluralizáveis. Já na amostra paralela do $\mathrm{PB}$, constituída por falantes da região metropolitana do Rio de Janeiro (em Copacabana e Nova Iguaçu), com falantes com um nível de escolaridade equivalente aos do PE (divididos entre o Ensino Fundamental, entre 5 e 8 anos de escolaridade; Ensino Médio, entre 9 e 11 anos; e Superior, mais de 11 anos), a frequência geral de aplicação da regra ficou um pouco acima de $90 \%$ (91,7\%), o que já configura um nível de variação estruturada na comunidade, segundo Labov (2003, p. 243). Os elevados graus de variação que se observam em outras variedades do $\mathrm{PB}$, como se verá aqui, eliminam qualquer paralelo com o que se observa em Portugal.

Além de sua fragilidade empírica, a hipótese de Naro e Scherre (2007) de que a variação na concordância nominal se originou de uma mudança fonética de perda do -s final que remonta ao latim vulgar não se sustenta, quer em sua argumentação histórica, quer na estrutura da variação observada atualmente no PB, como demonstrado por (2012a). Assim, é cada vez mais aceita a hipótese de que a variação nas regras de concordância nominal e verbal que se observa hoje no PB se originou durante a formação da sociedade brasileira, com base na aquisição imperfeita do português, como segunda língua (L2), por milhões de índios aculturados e africanos escravizados, e na nativização desse modelo de L2 entre os seus descendentes (LUCCHESI, 2008, 2009, 2012b, 2015).

Isso vai ao encontro do princípio geral, já referido no início da seção anterior, de que o resultado mais geral das situações de contato massivo é uma simplificação morfológica, tendo como ponto de partida a aquisição de uma L2 em situações de aprendizado natural e não orientado (MCWHORTER, 2007; TRUDGILL, 2001, 2009; 2013). Como afirmou Trudgill: 
Assim como a complexidade aumenta através do tempo e sobrevive como resultado das incríveis habilidades de aquisição da linguagem das crianças, a complexidade desaparece como o resultado das paupérrimas habilidades dos adultos na aquisição da linguagem. Contato linguístico entre adultos implica aquisição da linguagem por adultos, a qual implica simplificação, que se manifesta mais notavelmente na perda da redundância e da irregularidade e no incremento da transparência. (TRUDGILL, 2001, p.372, tradução nossa)

O contato massivo por meio do qual o português foi adquirido por milhões de indígenas aculturados e africanos escravizados já adultos, durante séculos, na formação da sociedade brasileira configura essa situação que produz a simplificação da língua. A perda da concordância de número no SN é uma instância óbvia de perda de redundância. Além disso, o fato de todos os crioulos de base portuguesa terem praticamente eliminado as regras de concordância nominal e verbal reforça a relação histórica entre a variação na concordância no PB e o contato entre línguas, pois há uma grande similaridade entre as condições em que o PB se formou e o processo de pidginização/crioulização $(\mathrm{P} / \mathrm{C})$, embora o contato entre línguas no Brasil não tenha atingido a radicalidade da P/C (LUCCHESI, 2012b, 2015, 2019a, 2019b).

Conquanto seja geral no Brasil, a falta de concordância predomina entre as classes populares, o que reforça a relação histórica com o contato entre línguas, já que os afro e índiodescendentes são majoritários entre as classes populares. Essas razões sócio-históricas explicam o estigma que se abate sobre a falta de concordância entre os indivíduos da elite letrada, o que evidencia o caráter até mesmo racista do preconceito linguístico no Brasil (LUCCHESI, 2011). Com isso, a realização ou não da concordância constitui uma das principais fronteiras no cenário da polarização sociolinguística do Brasil, no qual, em um extremo, encontra-se a norma culta e, no outro, a norma popular. Aquela se caracteriza por uma alta frequência de emprego das regras de concordância, enquanto esta se define por uma frequência de aplicação da regra bem mais baixa (LUCCHESI, 2012b, 2015).

Embora haja muitas análises sobre a variação na concordância de número no $\mathrm{SN}$, grande parte delas privilegiam ou mesmo se restringem à abordagem atomística ou mórfica, 
pois consideram que ela é mais profícua para identificar os condicionamentos estruturais do fenômeno, nomeadamente, a posição do constituinte no SN que recebe a marca de plural e a saliência fônica (maior diferença morfofonológica entre a forma do singular e do plural dos termos que se flexionam em número). Entretanto, essa abordagem só retrata indiretamente o fenômeno da concordância no SN, focalizando apenas a marcação do plural nos constituintes do SN. Isso tem dificultado a comparação dos resultados dos diversos estudos e a composição de um quadro geral que possa projetar o fenômeno no cenário sociolinguístico do país, como (2015, p. 246-264) fez com a concordância verbal. De qualquer forma, vale à pena observar a distribuição social do fenômeno nas diversas variedades do PB.

No que tange ao encaixamento social, as análises variacionistas sobre o fenômeno no Brasil possibilitam identificar alguns condicionamentos mais gerais. $\mathrm{Na}$ medida em que a falta de concordância é um fenômeno socialmente estigmatizado, a escola se torna um fator de difusão da concordância. Consequentemente, o maior nível de escolaridade se correlaciona com uma maior frequência de uso da regra em praticamente todos os estudos (SHERRE, 1988; NARO; SCHERRE, 2006; BRANDÃO, 2011, 2013; LOPES, 2015; OUSHIRO, 2015, entre outros). Levados pela visão da deriva secular, muitos estudos sociolinguísticos adotaram a hipótese de uma perda gradual das marcas de concordância (NARO, 1981), porém os resultados quantitativos têm contrariado essa hipótese ao indicar uma mudança em progresso no sentido do incremento das marcas de plural (BRANDÃO, 2011, 2013; ALMEIDA, 2018, entre outros), o que vai ao encontro da visão aqui adotada sobre a origem do fenômeno.

No que concerne à variável gênero/sexo, Andrade (2003, p. 129) observou, em estudo de uma variedade rural, que "os homens realizam mais a concordância do que as mulheres", contrariando a maioria das análises feitas em centros urbanos, nas quais as mulheres é que empregam com maior frequência a regra de concordância (SCHERRE, 1988; NARO; SCHERRE, 2006; BRANDÃO, 2011, 2013; OUSHIRO, 2015). Todavia, entende-se que qualquer conclusão sobre o efeito da variável sexo/gênero deve estar rigorosamente encaixada em um contexto social específico, a fim de evitar a abstração 
${ }^{6}$ Todos os exemplos serão retirados da base de dados da análise. em demasia (ECKERT; MCCONNELL-GINET, 2010, p. 94). Nesse sentido, a análise sociolinguística aqui desenvolvida buscou interpretar o resultado de cada variável social nas especificidades do universo sociocultural da comunidade de fala estudada.

\section{A variação na concordância de número no português rural da Serra Fluminense no contexto da polarização sociolinguística do Brasil}

Na abordagem sintagmática da variação na concordância de número no $\mathrm{SN}$, a variável dependente é definida em termos binários: (i) com concordância - quando todos os constituintes flexionáveis do SN exibiram a marca de plural; (ii) sem concordância - quando ao menos um constituinte flexionável do SN deixou de exibir a marca de plural; como se vê nos seguintes exemplos:

\section{SNs com concordância:}

1. ... a maiuria das atividades é voltada para a agricultura. ${ }^{6}$

2. Convivo com os meus dois irmãos.

\section{SNs sem concordância:}

3. Qual agrômo que tá nas lavôra visitando o produtô?

4. Todos os dia a rotina é essa.

Na amostra de fala vernácula analisada, foram encontradas 1.668 ocorrências de sintagmas nominais no plural. A regra de concordância foi aplicada totalmente em 802 ocorrências, o que representa uma frequência geral de aplicação da regra de $48 \%$ do total, como se observa na Tabela 1.

Tabela 1 - Frequência da concordância de número no SN, no português rural da Serra Fluminense

\begin{tabular}{lcc}
\hline $\begin{array}{l}\text { Aplicação da regra de } \\
\text { concordância }\end{array}$ & $\mathbf{N}^{\text {o }}$ de ocorrências/Total & Frequência \\
\hline Sim & $802 / 1.668$ & $\mathbf{4 8 , 1} \%$ \\
Não & $866 / 1.668$ & $\mathbf{5 1 , 9 \%}$ \\
\hline
\end{tabular}

Fonte: elaboração própria

A frequência geral de aplicação da regra na comunidade ficou ligeiramente abaixo da metade $(48,1 \%)$, um índice 
bem inferior ao que Brandão (2013) encontrou na região metropolitana da capital do Estado, tanto no bairro nobre de Copacabana quanto em uma localidade de sua periferia, de nível socioeconômico bem mais baixo, Nova Iguaçu, com as frequências de 92,4 e 92,1\%, respectivamente. Não obstante que o nível médio de escolaridade dos informantes de Brandão seja mais elevado do que o dos sujeitos dessa análise, que só têm o Ensino Fundamental ou Médio, enquanto a amostra de Brandão inclui falantes universitários, a grande diferença na frequência de emprego da regra deve ser explicada, também, pela dicotomia rural-urbano, pois o ambiente urbano favorece mais a difusão da norma padrão da língua do que o ambiente rural, que favorece mais a conservação das variedades vernaculares. Nesse sentido, mesmo considerando apenas os resultados dos falantes da amostra de Brandão com Ensino Fundamental e Médio, a frequência de uso da regra só cai até no máximo $80 \%$, comprovando que a divisão campo-cidade impacta na difusão da norma padrão e estrutura a atual polarização sociolinguística do Brasil.

Em um outro extremo, a análise sociolinguística de Andrade (2003, p. 105) sobre a comunidade rural afro-brasileira de Helvécia, no sul do Estado da Bahia, identificou uma frequência de aplicação da regra no SN como um todo de apenas $9 \%$ do total. Essa comunidade, já referida na primeira seção deste artigo, faz parte do que se denominou português afrobrasileiro (LUCCHESI; BAXTER; RIBEIRO, 2009). A comparação com esse estudo é particularmente significativa, pois se trata de duas variedades do português popular brasileiro (PPB) com a participação de colonos suíços e alemães em sua história. Contudo, deve-se fazer uma distinção crucial entre as duas. Helvécia é formada, em quase sua totalidade, por descendentes diretos de africanos escravizados, que se mantiveram isolados por muito tempo, praticando apenas uma agricultura de subsistência; havendo, portanto, uma relação muito direta com as mudanças induzidas pelo contato linguístico, o que explica o baixíssimo emprego da regra nessa comunidade.

Já na comunidade rural de Nova Friburgo, a presença negra parece ter sido reduzida, de modo que a relação histórica com o contato é bem mais mediada e indireta. Além disso, a diferença histórica entre Helvécia e Nova Friburgo é reforçada pela diferença entre o grau de desenvolvimento socioeconômico 
das regiões em que se situam as duas comunidades; estando a cidade serrana do Rio de Janeiro em uma das regiões mais desenvolvidas do país, enquanto o Nordeste é tradicionalmente uma região de menor desenvolvimento socioeconômico. Isso também explica a grande diferença na frequência de aplicação da regra de concordância entre as duas comunidades.

Portanto, no panorama do fenômeno da concordância nominal de número na polarização sociolinguística do Brasil, tem-se, no topo da pirâmide social, a elite letrada dos grandes centros urbanos, que emprega a regra de concordância com uma frequência superior a $90 \%$ do total de ocorrências. Essa frequência já cai nos centros urbanos, na medida em que diminui o nível de escolaridade dos falantes, até o patamar de $80 \%$ do total, entre os falantes com 5 a 8 anos de escolaridade (BRANDÃO, 2013, p. 72). Já na zona rural das regiões mais ricas do país, como é caso da comunidade aqui estudada, a frequência de aplicação da regra cai para cerca de 50\% do total de ocorrências. Esse percentual cai à medida que se passa para a zona rural das regiões mais pobres do país, até chegar ao baixíssimo patamar de menos de 10\% de frequência de aplicação da regra, em uma comunidade rural formada por descendentes diretos de africanos escravizados, que se manteve isolada, praticando uma cultura de subsistência. Todo esse cenário reforça claramente a visão aqui adotada de que a variação que afeta, hoje, os mecanismos morfossintáticos da concordância no PB teve a sua origem em mudanças induzidas pelo contato entre línguas durante a formação histórica da realidade sociolinguística brasileira. Essa hipótese também foi confirmada pela análise sociolinguística do fenômeno na comunidade de fala aqui em foco.

\section{A análise quantitativa do encaixamento social do fenômeno variável}

A análise quantitativa dos condicionamentos sociais da variação na concordância nominal de número no português rural do município de Nova Friburgo, na Região Serrana do Estado do Rio de Janeiro, foi feita com o programa de cálculo multivariado VARBRUL, em sua versão GoldVarb, que seleciona as variáveis independentes estatisticamente relevantes e mensura a interferência de cada fator sobre o 
fenômeno variável em foco, ponderando a ação simultânea de todos os demais fatores relevantes (cf. GUY; ZILLES, 2007).

Em se tratando das variáveis sociais, optou-se por garantir as categorias sobre as quais a Sociolinguística vem refletindo rotineiramente, mas com algumas especificidades: sexo; faixa etária, considerando apenas dois grupos: o de pais, entre 35 e 55 anos, e o dos filhos, entre 14 e 19 anos - portanto, é melhor se referir a essa variável, não como idade, mas como geração; e escolarização, em que os falantes se distribuíram por três níveis de escolaridade: $1^{\circ}$ Segmento do Ensino Fundamental (completo ou incompleto); $2^{\circ}$ Segmento do Ensino Fundamental (completo ou incompleto); e Ensino Médio (em curso). Além dessas, foram consideradas também: a aglomeração ou bairro onde o informante residia, garantindo que todo o território rural identitariamente identificado pelos moradores pudesse ser contemplado; a comunidade de prática religiosa e associativa da qual o entrevistado fazia parte; e o cargo ou função ocupados nesses grupamentos. Com exceção dessa última, todas as variáveis foram consideradas estatisticamente relevantes pelo GoldVarb.

Para as variáveis independentes (ou grupo de fatores) com valor estatístico, o GoldVarb fornece, para cada fator do grupo, as frequências brutas de ocorrência do fenômeno em termos percentuais, bem como o peso relativo (PR), índice resultante do cálculo multivariado que computa a influência simultânea de todos os fatores conjuntamente. Os valores obtidos para cada variável explanatória selecionada pelo programa serão apresentados e analisados a seguir.

\section{Um caso de mudança em progresso}

No plano do encaixamento social de um fenômeno linguístico variável, as formas variantes podem permanecer em variação na comunidade indefinidamente, ou uma variante pode se expandir a ponto de seu uso se tornar categórico. No primeiro caso, tem-se uma situação de variação estável; no segundo, um processo de mudança em progresso. A análise sociolinguística procura deslindar essas situações observando a distribuição das variantes linguísticas pela estrutura social da comunidade de fala analisada e identificar potenciais 
7 O nível de significância é um índice utilizado no cálculo probabilístico para medir o nível de confiabilidade dos resultados. Geralmente, um resultado estatístico é considerado confiável quando seu nível de significância é inferior a .050. E quanto mais próximo de zero, maior a confiabilidade do resultado em termos estatísticos. processos diacrônicos de mudança linguística, por meio de uma análise sistemática da variação sincrônica, observada em um determinado momento na língua, no que se denominou análise da mudança em tempo aparente (LABOV, 2008[1972], 1981, 1994, 2001b).

A análise em tempo aparente se fundamenta, sobretudo, nos resultados da variável idade dos falantes. A diferença no comportamento linguístico de gerações diferentes é tomada como um reflexo de um potencial processo de mudança, sendo o incremento do emprego da variante inovadora, na medida em que se passa dos membros mais velhos para os membros mais novos da comunidade, a principal evidência de um processo de mudança em progresso (LABOV, 2008[1972], 1981, 1994, 2001b).

Em face da hipótese geral de que estaria em curso na comunidade uma mudança no sentido do aumento do uso da regra, o resultado esperado seria os jovens empregando mais a regra do que seus pais. Por um problema na constituição da amostra, houve uma superposição entre geração e escolaridade. Por isso, na primeira rodada, o GoldVarb selecionou primeiramente a variável escolaridade, e, quando essa cruzou com a variável geração, o programa descartou a última, por conta da superposição. Em vista disso, foi feita uma nova rodada, sem a variável escolaridade. Dessa vez, a geração foi a terceira selecionada como mais significativa em termos estatísticos entre todas, e a segunda variável social selecionada, atrás apenas da variável sexo. Essa última rodada teve um nível de significância (.008) melhor do que aquela que incluía todas as variáveis inicialmente propostas $(.031) .{ }^{7}$ Seguem os resultados obtidos:

Tabela 2 - Aplicação da regra de concordância de número no SN no português rural da Serra Fluminense em função da geração do falante

\begin{tabular}{lccc}
\hline Geração & $\begin{array}{c}\mathbf{N}^{\mathbf{o}} \text { de } \\
\text { ocorrências/Total }\end{array}$ & Frequência & Peso relativo \\
\hline Filhos & $553 / 997$ & $57,5 \%$ & .590 \\
Pais & $229 / 671$ & $34,1 \%$ & .368 \\
TOTAL & $\mathbf{8 0 2 / 1 . 6 6 8}$ & $\mathbf{4 8 , 1 \%}$ & \\
\hline
\end{tabular}

Nível de significância: .008

Fonte: elaboração própria 
Os resultados da variável geração foram favoráveis à hipótese de mudança em progresso no sentido da implementação da regra de concordância de número na comunidade, pois os indicadores foram mais elevados entre os filhos do que entre os pais, tanto em termos percentuais como em PRs. Os filhos empregaram a regra de concordância de número no SN numa frequência geral de $57,5 \%$, enquanto os pais só o fizeram em $34,1 \%$ dos casos. Os PRs confirmaram os percentuais, com .590 para os filhos e .368 para os pais. $\mathrm{O}$ incremento do uso da regra entre os mais jovens é o primeiro indício de mudança em progresso na abordagem em tempo aparente. Todavia, esse diagnóstico precisa ser confirmado pelos resultados das demais variáveis sociais.

\section{O papel da escola}

A superposição entre escolaridade e faixa etária é muito frequente nas amostras de fala recolhidas no Brasil. Cardoso (2015, p. 27-28) alerta para o fato de que, no Brasil, o controle da variável idade está sujeito à interferência da escolaridade. Isso exige, portanto, um maior cuidado no cruzamento dos dados e na análise dos resultados, visto que a variação apresentada pela geração de jovens, na atualidade, pode estar associada ao seu maior acesso à educação formal. A instituição escolar pode provocar mudanças na fala individual, ocasionando variação estilística, e na atividade discursiva da comunidade; ao mesmo tempo em que atua como difusora das formas consideradas de prestígio (VOTRE, 2007, p. 51), fomentando, na maioria das vezes, o estigma social sobre as formas da linguagem popular e o preconceito linguístico. Nesse sentido, esperava-se que um maior nível de escolarização elevasse o uso da regra de concordância. No entanto, os resultados não foram tão óbvios: 
Tabela 3 - Aplicação da regra de concordância de número no SN no português rural da Serra Fluminense em função do nível de escolaridade

\begin{tabular}{lccc}
\hline Escolaridade & $\begin{array}{c}\mathbf{N}^{\mathbf{0}} \text { de } \\
\text { ocorrências/Total }\end{array}$ & Frequência & Peso relativo \\
\hline Ensino Médio & $573 / 997$ & $57,5 \%$ & $\mathbf{6 0 7}$ \\
$\mathbf{2}^{\mathbf{o}}$ segmento Ensino & $49 / 83$ & $59 \%$ & $\mathbf{. 6 2 7}$ \\
$\begin{array}{l}\text { Fundamental } \\
\mathbf{1}^{\mathbf{o}} \text { segmento Ensino }\end{array}$ & $180 / 588$ & $30,6 \%$ & $\mathbf{. 3 0 7}$ \\
Fundamental & $\mathbf{8 0 2 / 1 . 6 6 8}$ & $\mathbf{4 8 , 1 \%}$ & \\
TOTAL &
\end{tabular}

Nível de significância: .031.

Fonte: elaboração própria

Segundo os resultados quantitativos, o efeito da escolaridade ocorre a partir do $2^{\circ}$ segmento do Ensino Fundamental e não se altera com a passagem do indivíduo para o Ensino Médio. Enquanto os informantes do $1^{\circ}$ segmento do Ensino Fundamental usam a regra de concordância em 30,6\% do total (PR de .307), os informantes do $2^{\circ}$ segmento empregam a regra em 59\% das ocorrências (PR de .627). Não há diferença no comportamento linguístico desses últimos em comparação com os informantes do Ensino Médio. Os percentuais são praticamente idênticos, até com uma ligeira elevação para os indivíduos do $2^{\circ}$ segmento do Ensino Fundamental: 59\% contra $57,5 \%$ e PR de .627 contra .607. Esses resultados apontam o $2^{\circ}$ Segmento do Ensino Fundamental como decisivo na aquisição dos padrões de concordância de número, como consequência de uma ampliação da consciência linguística em relação ao

${ }^{8}$ Cabe destacar que a entrevistadora era professora de Língua Portuguesa do Ensino Médio daqueles indivíduos e não se pode aferir o quanto isso interferiu no nível de monitoramento da fala no momento do inquérito. padrão normativo. ${ }^{8}$

\section{O papel das mulheres na mudança linguística}

Sobre a interferência do gênero/sexo dos falantes no processo de implementação da mudança linguística, Paiva afirma que:

A análise da dimensão social da variação e da mudança não pode ignorar (...) que a maior ou menor ocorrência de certas variantes, (...) estejam associados ao gênero/sexo do falante e à forma de construção social dos papéis feminino e masculino. (PAIVA, 2007, p.33) 
A diferença no comportamento linguístico entre homens e mulheres é normalmente associada à forma diferenciada como eles e elas reagem no plano subjetivo da avaliação social das variantes linguísticas. Nesse sentido, Dália (2018, p. 372) já havia detectado que as mulheres das comunidades do $3^{\circ}$ Distrito, principalmente as mais velhas, julgavam mais negativamente sua própria variedade linguística do que os homens. Diante disso, esperava-se que elas tenderiam a monitorar mais a fala e, portanto, aplicariam com maior frequência a concordância nominal de número. Os dados encontrados foram:

Tabela 4 - Aplicação da regra de concordância de número no SN no português rural da Serra Fluminense em função do sexo do falante

\begin{tabular}{lccc}
\hline Sexo & $\begin{array}{c}\mathbf{N}^{\mathbf{o}} \text { de } \\
\text { ocorrências/Total }\end{array}$ & Frequência & Peso relativo \\
\hline Mulheres & $509 / 844$ & $60,3 \%$ & .700 \\
Homens & $293 / 824$ & $35,4 \%$ & .295 \\
TOTAL & $\mathbf{8 0 2 / 1 . 6 6 8}$ & $\mathbf{4 8 , 1 \%}$ & \\
\hline
\end{tabular}

Nível de significância: .043.

Fonte: elaboração própria

Os resultados quantitativos confirmaram a hipótese, já que as mulheres empregam bem mais a regra de concordância de número do que os homens. Em termos percentuais, a frequência média de uso da regra é quase o dobro entre as mulheres do que entre os homens: $60,3 \%$, contra apenas $35,4 \%$. A expressiva diferença nos PRs (.700 contra .295) reflete essa disparidade em termos percentuais. Esses resultados vão ao encontro do resultado geral nas análises sociolinguísticas conduzidas na América do Norte e na Europa Ocidental (CHAMBERS, 1995, p. 102-103), porém Lucchesi (2015, p. 5758) observa que "a generalização alcançada [nesses] estudos é negada pelos resultados das análises sociolinguísticas levadas a cabo na periferia das grandes cidades brasileiras e nas comunidades rurais afro-brasileiras isoladas", pois "nesses grupos sociais, são os homens que lideram a mudança em direção às formas de prestígio, e não as mulheres". E conclui: 
o papel da variável sexo só pode ser compreendido à luz da compreensão do processo social como um todo em que se definem claramente suas especificidades, como o papel social atribuído a cada gênero. Dessa forma, a mudança linguística, enquanto processo histórico, pode assumir diferentes configurações sociais, relativamente a variáveis como sexo, idade ou classe social, consoante as especificidades do contexto sócio-histórico em que essa mudança se implementa. (LUCCHESI, 2015, p. 57-58)

Dessa forma, esta análise buscou explicitar as distinções de gênero na comunidade analisada para compreender melhor o papel da mulher na implementação do processo de mudança aqui focalizado. Etnograficamente, percebeu-se que, na região, o trabalho tinha uma divisão de gênero bem estabelecida. As mulheres eram sempre responsáveis pela organização da casa, assim como cabia às meninas essa tarefa quando não estavam estudando. Eram as mães que encaminhavam e supervisionavam a vida escolar dos filhos. Grande parte delas também era responsável pela administração da produção agrícola, como organizar notas e pedidos de mercadorias. No que se refere ao trabalho no campo, não havia distinção. Homens e mulheres mais velhos pareciam lidar em conjunto com a produção agrícola propriamente dita. No entanto, cabia aos homens a responsabilidade do transporte de mercadorias, tanto na própria região como para a capital e outras cidades.

Outro fator interessante, é que, para os meninos, permanecer em atividades ligadas à agropecuária parecia se apresentar como um caminho profissional, enquanto as meninas, embora demonstrassem muito orgulho e relações identitárias com sua comunidade, não demonstravam esse interesse. É possível que as meninas tenham influenciado bastante o resultado, já que elas demonstram ter uma rotina maior fora da comunidade. Muitas fazem cursos na zona urbana e mantêm trabalhos fora da agricultura, como em restaurantes e pousadas, o que as coloca em contato direto com outras variedades da língua, enquanto a maioria dos meninos se mantêm mais ligados às atividades agropecuárias.

Daí se podem extrair algumas possíveis explicações para a variação diagenérica aqui encontrada. Os homens, sobretudo 
os mais velhos, estão mais ligados às atividades agropecuárias, sendo mais refratários às influências de cima para baixo e de fora para dentro, conservando uma atitude mais voltada para a conservação do vernáculo da comunidade. Por outro lado, as mulheres estão mais expostas ao ambiente letrado, seja pela vida escolar dos filhos, seja pela escrita nos talões de notas. Assim, estão, de alguma forma, mais sujeitas à imposição da norma padrão. Por fim, ao que parece, as meninas estão associando sua fala àquelas consideradas de prestígio em função de sua vivência, profissional e social, em ambientes externos.

\section{A variável aglomeração ou bairro rural}

Para o recorte do campo da pesquisa, optou-se por eleger, em uma microanálise, não locais isolados, mas conjuntos, denominados bairros ou aglomerados rurais (CANDIDO, 2010; COMERFORD, 2005), que se estabeleceram naturalmente por meio de suas relações sociais, ou institucionalmente por meio de instituições religiosas e ou associativas. Sabia-se que a comunidade contava com 12 localidades, já alvo de algumas investigações sociais (FRAZÃO, 2015; OLIVEIRA, 2011). Entretanto, como aqui se queria partir de uma análise etnográfica rural, buscou-se estabelecer, por meio do que era apresentado pelos próprios moradores, os critérios de ruralidade para a seleção dos bairros ou aglomerados que formariam a comunidade linguística aqui delineada. Chegouse, então, às seguintes características que deveriam ser consideradas para a eleição das localidades: a maior parte do trabalho ligado à agropecuária; a infraestrutura de serviços; os laços afetivos, de parentesco e de representação social entre os moradores; e a manutenção de hábitos comportamentais em oposição aos centros urbanos. Nesse sentido, selecionaram-se 6 aglomerados rurais: (A) Barracão dos Mendes; (B) Alto de Salinas, Salinas e Patrocínio; (C) Santa Cruz e Centenário; (D) Três Picos e Jaborandi; (E) Baixada de Salinas e Campestre; e (F) São Lourenço, São Felipe e Fazenda Schuenck. A hipótese inicial era de que os aglomerados $(\mathrm{B})$ e $(\mathrm{F})$, mais afastados do perímetro urbano pelas estradas principais, demonstrassem maior conservação vernacular e, portanto, menor frequência na concordância de número nos SNs; e o aglomerado (A), em 
contraposição, maior índice de concordância. No entanto, durante os inquéritos, era comum que os informantes indicassem a comunidade (D) como a mais identitária linguisticamente. Muitos deles a viam como diferenciada das demais e afirmavam conhecer seus moradores apenas pelo seu jeito de falar que era mais, segundo eles, "tradicional" e "roceiro". Indicou-se, assim, a possibilidade de Três Picos e Jaborandi apresentarem, também, um índice baixo de concordância. Seguem, pois, os resultados:

Tabela 5 - Aplicação da regra de concordância de número no SN no português rural da Serra Fluminense em função da localidade do falante

\begin{tabular}{lccc}
\hline Localidades & $\begin{array}{c}\mathbf{N}^{\mathbf{0}} \mathbf{d e} \\
\text { ocorrências/Total }\end{array}$ & Frequência & Peso relativo \\
\hline Três Picos e Jaborandi & $192 / 352$ & $54,5 \%$ & .725 \\
$\begin{array}{l}\text { Baixada de Salinas e } \\
\text { Campestre }\end{array}$ & $130 / 239$ & $54,4 \%$ & .659 \\
$\begin{array}{l}\text { S. Lourenço, S. Felipe e } \\
\text { Faz. Schuenck }\end{array}$ & $115 / 825$ & $40,4 \%$ & .463 \\
Barracão dos Mendes & $132 / 240$ & $55 \%$ & .434 \\
$\begin{array}{l}\text { Alto de Salinas, Salinas } \\
\text { e Patrocínio }\end{array}$ & $83 / 235$ & $35,3 \%$ & .389 \\
Santa Cruz e Centenário & $150 / 317$ & $47,3 \%$ & .289 \\
TOTAL & $\mathbf{8 0 2 / 1 . 6 6 8}$ & $48,1 \%$ & \\
\hline
\end{tabular}

Nível de significância: .031.

Fonte: elaboração própria

Contrariando a hipótese dos moradores, as localidades de Três Picos e Jaborandi e Baixada de Salinas e Campestre são aquelas em que a regra de concordância é mais empregada, com PR de .725 para as duas primeiras e PR de .659 para as três últimas. A frequência de uso da regra em todas elas é praticamente a mesma, oscilando entre 54,5 e $54,4 \%$. A diferença nos pesos relativos ocorreu no cruzamento entre essa variável e a variável religiosidade, quando o PR das localidades de Três Picos e Jaborandi subiu de .696 para .725, e o PR das localidades de Baixada de Salinas e Campestre caiu de .702 para .659. Isso se deve certamente à falta de ortogonalidade entre essas duas variáveis, já que elas não foram estratificadas na constituição da amostra. Entretanto, esse problema de distribuição dos informantes não impede que se coloquem 
essas localidades como aquelas em que a regra de concordância é mais empregada, pois a frequência de uso nelas é maior do que a frequência geral da amostra, que é de $48,1 \%$.

Como o aglomerado Baixada de Salinas e Campestre não foi considerado em nenhuma das hipóteses, cabem aqui algumas reflexões. Ele se localiza entre os grupamentos (D) e (F), exatamente opostos em relação à frequência de concordância. Então, não pode ser encarado como uma espécie de "zona de amortecimento" dos padrões de concordância. Todavia, há uma semelhança com o aglomerado vizinho, Três Picos e Jaborandi: ambos são limítrofes à escola de Ensino Médio da região e os bairros mais próximos ao Parque Estadual dos Três Picos. Daí se podem ensaiar algumas explicações: (i) a escola, que é um ponto de experimentações científicas, além de trazer o contato com um ambiente acadêmico, traz inúmeros sujeitos externos que passam a ter contato cotidiano com as comunidades circunvizinhas; (ii) por abranger uma área explorada turisticamente, com algumas pousadas e restaurantes, a troca linguística é maior aqui do que em outros bairros da comunidade. $\mathrm{O}$ "forasteiro" pode estar interferindo no vernáculo local. Por outro lado, Baixada de Salinas, Campestre e Três Picos compõem a mesma associação de agricultores, o que também pode favorecer o compartilhamento linguístico.

Outra disparidade que ocorreu entre o percentual e o PR foi com a localidade de Barracão do Mendes, com um percentual de uso da rega de 55\% e um PR de apenas .434. Era de se esperar que o PR dessa localidade fosse similar ao das primeiras, ou até um pouco maior, já que sua frequência de uso da regra é ligeiramente superior às demais. Aqui, mais uma vez, houve um problema de estratificação na amostra. Como nessa localidade a maioria dos informantes é de mulheres, o PR caiu de .584 para .503 quando a variável sexo foi selecionada no cruzamento. Depois ainda caiu de .503 para .474 quando a variável participação em associação de moradores e/ou agricultores foi selecionada para o cruzamento, já que o convívio associativo aqui é pequeno. E ainda caiu para .434 no cruzamento com a variável religião. Por conta desses problemas, vai-se considerar o percentual, e não os PRs, na análise dessa variável. Assim, pode-se colocar a localidade de Barracão do Mendes, a mais próxima do perímetro urbano, entre aquelas 
em que a concordância de número no SN é mais empregada, confirmando uma das hipóteses originais. A maior facilidade de deslocamento e a oferta de outros postos de trabalho podem estar interferindo nos usos linguísticos do bairro.

Ainda tomando como base a frequência de uso da regra, medida em termos percentuais, pode-se observar que, nas localidades de Santa Cruz e Centenário, a regra de concordância é usada em uma frequência $(47,3 \%)$ ligeiramente inferior à frequência geral da amostra (48,1\%). Já nas localidades de São Lourenço, São Felipe e Fazenda Schuenck, a frequência de uso da regra cai significativamente, ficando em $40,4 \%$. Alto de Salinas, Salinas e Patrocínio são aquelas em que a frequência de uso da regra é a mais baixa, apenas $35,3 \%$. Os dados confirmam a hipótese inicial, já que as duas últimas são as comunidades mais afastadas, nas quais ficam os pontos finais das linhas de transporte público, não havendo outros bairros depois delas, o que faz com que o contato entre os aglomerados seja menor do que nas outras localidades.

\section{As variáveis religião e participação em associação de moradores e agricultores}

Essas duas variáveis serão analisadas juntas, pois foram embasadas em um mesmo princípio. $\mathrm{O}$ objetivo era testar se a participação assídua em uma comunidade de prática interferiria na variedade dos falantes (ECKERT; MCCONNELL, 2010; ECKERT, 2012). A hipótese inicial desses dois grupos de fatores era a de que o efetivo engajamento em um grupamento favoreceria o incremento da aplicação das regras de concordância, principalmente, naqueles nos quais a fala pública fosse incentivada. Os resultados quantitativos estão dispostos a seguir juntamente com sua análise:

Tabela 6 - Aplicação da regra de concordância de número no SN no

${ }^{9}$ Não havia uma pré-definição do elenco de opções de religiões. Estão sendo apresentadas aqui os indicativos extraídos do conteúdo da entrevista. Portanto, as demais religiões simplesmente não foram mencionadas pelos entrevistados. português rural da Serra Fluminense em função da religião do falante

\begin{tabular}{lccc}
\hline Religião $^{9}$ & $\begin{array}{c}\mathbf{N}^{\mathbf{o}} \text { de } \\
\text { ocorrências/Total }\end{array}$ & Frequência & Peso relativo \\
\hline Protestante & $555 / 980$ & $56,6 \%$ & .537 \\
Sem religião & $70 / 146$ & $47,9 \%$ & .548 \\
Católica & $177 / 542$ & $32,7 \%$ & .421 \\
TOTAL & $\mathbf{8 0 2 / 1 . 6 6 8}$ & $48,1 \%$ & \\
\hline
\end{tabular}

Nível de significância: .031.

Fonte: elaboração própria 
Os problemas de estratificação da amostra também enviesaram os PRs nessa variável, principalmente porque os aglomerados tendem a concentrar, por conta da proximidade e da força social de suas instituições religiosas, mais moradores de uma crença do que de outra. Além disso, o número de jovens sem religião foi maior do que o quantitativo de informantes mais velhos que alegaram o mesmo. Desse modo, a análise será feita com base nos percentuais, o que não prejudicará a testagem diante da hipótese apresentada.

A aplicação da regra de concordância é significativamente maior entre os protestantes do que entre católicos ou sem religião. A hipótese aqui parece ter sido confirmada, principalmente, se levado em conta o modo de participação exigido por cada uma das duas orientações religiosas na comunidade. Além dos cultos, o grupo dos protestantes alegou participar de outros círculos sociais dentro da própria igreja. Há grupamentos apenas para mulheres, só para homens, somente para jovens ou crianças, bandas musicais etc. Ou seja, a participação dificilmente se circunscreve apenas ao dia do culto, o que motiva também a assunção de diferentes papéis sociais por um único agente, o contato com materiais, inclusive de leitura, e, principalmente, o intercâmbio entre instituições fora da região. Em contrapartida, é mais comum entre os católicos, até entre os mais assíduos, a frequência apenas à missa e o contato religioso restrito ao ambiente da igreja. Talvez, por isso, os dois grupos apresentem um comportamento linguístico tão diverso.

Já os dados de participação em associação apontam para um outro caminho:

Tabela 7 - Aplicação da regra de concordância de número no SN no português rural da Serra Fluminense em função da participação em

\begin{tabular}{lccc}
\multicolumn{4}{c}{ associações } \\
\hline $\begin{array}{l}\text { Participação em } \\
\text { associações }\end{array}$ & $\begin{array}{c}\mathbf{N}^{\mathbf{0}} \text { de } \\
\text { ocorrências/Total }\end{array}$ & Frequência & Peso relativo \\
\hline Sim & $381 / 940$ & $40,5 \%$ & .379 \\
Não & $366 / 616$ & $59,4 \%$ & .680 \\
TOTAL & $\mathbf{8 0 2 / 1 . 6 6 8}$ & $48,1 \%$ & \\
\hline
\end{tabular}

Nível de significância: .031.

Fonte: elaboração própria 
Nessa variável, os problemas de estratificação da amostra não interferiram significativamente no cálculo multivariado dos pesos relativos. Há uma razoável correspondência entre os PRs e os resultados percentuais. Os últimos indicam que os informantes que não participam de associações usam a regra de concordância em uma frequência maior do que aqueles que participam, com uma frequência de 59,4\% entre aqueles e de 40,5\% entre estes. Os PRs são proporcionais aos valores percentuais, com .680 para os que não participam das associações e apenas .379 para os que participam.

A explicação para essa diferença se encontra no grupo que frequenta as associações. A maioria dos associados assíduos às reuniões é de homens mais velhos, ou seja, aqueles que menos empregam as regras de concordância. Tal característica sugere outra perspectiva de interpretação. Esse grupo estaria mais infenso às influências externas, às pressões de baixo para cima e de fora para dentro da comunidade, de modo que a manutenção do seu vernáculo funcionaria como uma forma de fortalecer a solidariedade entre os membros do grupo, no que Milroy e Milroy (1997) denominaram normatização vernacular. Portanto, considerando, por um lado, as igrejas e, por outro, as associações, pode-se concluir que a comunidade de prática parece influenciar tanto na reação à mudança quanto na sua implementação. A chave está em observar como, em cada comunidade de prática, os seus membros se relacionam com o que vem do mundo exterior.

\section{Considerações finais}

A análise em tempo aparente da variação na concordância de número no $\mathrm{SN}$ em uma comunidade de fala rural da Região Serrana do Estado do Rio Janeiro revelou um processo de mudança de cima para baixo e de fora para dentro, nos termos de Labov (2008[1972], 2001b). Todos os resultados das variáveis sociais concorreram para a composição desse cenário. Os jovens, que no geral são mais escolarizados, apresentaram o maior nível de uso da regra de concordância, conforme o padrão normativo da língua. As especificidades do gênero feminino, não apenas em sua relação com a escolarização, mas também no que concerne às atividades profissionais que assumem e sua relação com o mundo exterior, também fizeram 
com que as mulheres liderassem o processo de mudança. A análise geográfica e etnográfica dos bairros rurais em que a comunidade se distribui também apontou para uma mudança de fora para dentro, ocorrendo um uso mais frequente da regra de concordância nos bairros com uma relação mais intensa com o mundo exterior. Essa relação mais intensa com o mundo exterior e uma maior prática de atividades letradas também explicam por que os indivíduos de religião protestante empregam mais a regra. Em um sentido inverso, o sentimento de solidariedade de grupo, entre agricultores mais velhos do sexo masculino, fez da associação um espaço de conservação do vernáculo rural.

Esse cenário de mudança em progresso no sentido do incremento da concordância nominal de número na comunidade vai ao encontro da visão segundo a qual, na formação histórica das variedades populares e rurais do PB, os mecanismos morfossintáticos de marcação redundante, como as regras de concordância, sofreram uma significativa erosão, em função do contato entre línguas. Todavia, atualmente esse processo estaria sendo revertido em função, sobretudo, da ação dos meios de comunicação de massa, da escolarização e de uma melhor integração dos segmentos populares nos mercados de trabalho e de consumo. Ademais, esse resultado contraria a hipótese da deriva secular que prevê que um processo gradual de perda das marcas morfológicas estaria em curso. Dessa forma, a análise reitera o que tem sido observado na maioria das análises sobre o PPB.

Contudo, este estudo tem um interesse especial por tratar de uma comunidade com uma composição étnica em que, para além dos elementos normalmente presentes na história do Brasil, também se insere o elemento helvético-germânico. Assim, um paralelo interessante ocorreu com a comunidade de Helvécia, que se formou alicerçada em grandes plantações de café estabelecidas, também, por colonos suíços e alemães, no extremo sul do Estado da Bahia, no século XIX. Contudo, ao contrário de Helvécia, uma comunidade de fala com características mais notáveis de um contato linguístico radical, a comunidade rural de Nova Friburgo exibe uma frequência muito maior de concordância, com a regra de concordância sendo aplicada em quase a metade das ocorrências, enquanto que a frequência de aplicação da regra em Helvécia é de apenas 
9\%. Para além de diferenças sócio-históricas entre as duas comunidades, essa diferença também se explica pelo nível de desenvolvimento socioeconômico da Região Serrana do Rio de Janeiro em comparação com a maioria das regiões rurais do Nordeste brasileiro. Não se deve, no entanto, pensar que o grau de variação em Nova Friburgo não seja significativo, pois observou-se uma forte clivagem entre os padrões linguísticos do campo e da cidade. Enquanto a frequência de aplicação da regra nessa comunidade rural fica em torno de 50\%, a frequência de uso da regra, na cidade do Rio de Janeiro, não é inferior a $80 \%$, entre os falantes com pelo menos cinco anos de escolaridade. Esse elevado grau de variação nas regiões do interior do Brasil, que tendem a conservar mais o seu vernáculo, aponta para um profundo processo de mudança induzida pelo contato ocorrido no passado. Em face do cenário observado em Portugal, em que as regras de concordância são praticamente categóricas, a correlação histórica entre o amplo e profundo quadro de variação do Brasil e o contato entre línguas é inexorável.

Portanto, esta análise sociolinguística permitiu vislumbrar um processo de mudança em curso no sentido da implementação da regra de concordância na comunidade, com base no encaixamento social do fenômeno variável na atualidade. Além disso, reuniu evidências empíricas que iluminam o processo de formação histórica das variedades rurais e populares do $\mathrm{PB}$, no qual o contato do português sobretudo com as línguas indígenas e africanas desempenhou um papel decisivo.

\section{REFERÊNCIAS}

ALMEIDA, Evanilda Marins. A variação da concordância nominal num dialeto rural. In: PAULA, Alessandra de; GOMES, Danielle Kely; SILVEIRA, Eliete Figueira Batista da; VIEIRA, Marcia dos Santos Machado; VIEIRA, Silvia Rodrigues. (org.). Uma História de Investigações sobre a Lingua Portuguesa: Homenagem a Silvia Brandão. São Paulo: Blucher, 2018.

ANDRADE, Patrícia Ribeiro de. Um fragmento da constituição sócio-histórica do português do Brasil: variação na concordância 
nominal de número em um dialeto afro-brasileiro. 2003. 147f. Dissertação (Mestrado em Letras e Linguística) - Instituto de Letras, Universidade Federal da Bahia, Salvador, 2003.

BON, Henrique. Os imigrantes: a saga do primeiro movimento migratório organizado rumo ao Brasil às portas da independência. Nova Friburgo: Imagem Virtual, 2004.

BRANDÃO; Silvia Figueiredo. Patterns of plural agreement within the Noun Phrase. Journal of Portuguese Linguistics, Lisboa, v. 12, n. 2, p. 51-100, 2013.

. Concordância nominal em duas variedades do português: convergências e divergências. Revista Veredas, Juiz de Fora, v.15, n.1, p.164-178, 2011.

BRANDÃO; Silvia Figueiredo; VIEIRA, Sílvia. Concordância nominal e verbal: contribuições para o debate sobre o estatuto da variação em três variedades urbanas do português. Alfa, São Paulo, v.56, n.3, p.1035-1064, 2012.

CANDIDO, Antonio. Os parceiros do Rio Bonito: estudos sobre o caipira paulista e a transformação dos seus meios de vida. 11. ed. Rio de Janeiro: Ouro sobre Azul, 2010.

CARDOSO, Denise Porto. Atitudes linguísticas e avaliações subjetivas de alguns dialetos brasileiros. São Paulo: Blucher, 2015.

CHAMBERS, Jack. Sociolinguistic Theory: linguistic variation and its social significance. Oxford: Blackwell, 1995.

COMERFORD, John Cunha. Comunidade Rural. In: MOTTA, Márcia. (org.). Dicionário da Terra. Rio de Janeiro: Civilização Brasileira, 2005.

DÁLIA, Jaqueline de Moraes Thurler. Atitudes, crenças e (auto) avaliação linguística de comunidades do $3^{\circ}$ Distrito de Nova Friburgo. Caderno Seminal Digital Especial, Rio de Janeiro, v. 30, no 30, p.345-399, Jan-Dez. 2018.

ECKERT, P. Three waves of variation study: the emergence of meaning in the study of sociolinguistic variation. Annual Review of Anthropology, v. 41, p. 87-100, 2012. Disponível em: 
https://www.annualreviews.org/doi/10.1146/annurevanthro-092611-145828. Acesso em: 04/01/2020.

ECKERT, Penélope; MCCONNELL, Sally. Comunidade de prática: lugar onde co-habitam linguagem, gênero e poder. In: OSTERMANN, Ana Cristina; FONTANA, Beatriz (org.). Linguagem, gênero e sexualidade: clássicos traduzidos. São Paulo: Parábola Editorial, 2010.

FERREIRA, Carlota. Remanescentes de um falar crioulo brasileiro. In: FERREIRA, Carlota et al. Diversidade do português do Brasil. Salvador: EDUFBA, 1984. p.21-32.

FERREIRA, Marieta de Moraes. Marianne Joset Salusse: uma mulher afrente de seu tempo. In: ARAÚJO, João Raimundo; LO BIANCO, Regina; COSTA, Ricardo da gama Rosa. Teia Serrana II: novos temas e novas abordagens. Nova Friburgo: Marca Gráfica Editora, 2019.

FRAZÃO, Gabriel Almeida. Um negociante das “Terras Frias": uma análise das estratégias de aquisição fundiária do português Antonio José Mendes (Nova Friburgo, 1860-1914). Revista Maracanan, Rio de Janeiro, n. 23, p. 59-82, jan/abr. 2020.

. "A Serviço da Formação do Jovem Rural": Desafios e Contradições Atuação do CEFFA CEA Rei Alberto I Como Agente do Desenvolvimento do Meio. 2015. 206f. Tese (Doutorado em Sociologia Rural) - Programa de Pós-graduação de Ciências Sociais em Desenvolvimento, Agricultura e Sociedade, Universidade Federal Rural do Rio de Janeiro, Seropédica, 2015.

Guy, Gregory Riordan; Zilles, Ana Maria Stahl. Sociolinguística Quantitativa. São Paulo: Parábola Editorial, 2007.

JOYE, Padre Jacob. Anotações sobre a viagem dos imigrantes suiços em 1819. Associação Fribourg-Nova Friburgo. Juiz de Fora: Ed. Juiz Forana, 2005.

LABOV, William. Principles of Linguistic Change. Volume 3: Cognitive and cultural factors. Oxford/Cambridge: Blackwell, 2010. 
. Padrões Sociolinguísticos. São Paulo: Parábola, 2008[1972].

Some sociolinguistic principles. In: PAULSTON, C. B.;

TUCKER, G. R. (org.). Sociolinguistics: the essential readings. Oxford: Blackwell, 2003. p. 235-250.

Principles of Linguistic Change: Social Factors. Oxford: Blackwell, 2001a.

. Principles of Linguistic Change: Cognitive and Cultural Factors. Oxford: Wiley Blackwell, $2001 \mathrm{~b}$.

Principles of linguistic change. Oxford; Cambridge: Blackwell, 1994.

What can be learned about change in progress from synchrony descriptions. In: SANKOFF, David; CEDERGREN, Henrietta (ed.). Variation Omnibus. Carbondale; Edmonton: Linguistic Research, 1981. p.177-199.

LISBOA, Edson de Castro. Café e escravidão em Nova Friburgo no Século XIX. In: ARAÚJO, João Raimundo de; MAYER, Jorge Miguel. Teia serrana: formação histórica de Nova Friburgo. Rio de Janeiro: Ao Livro Técnico, 2003.

LOPES, Norma da Silva. O mecanismo da variação da concordância no português: observações quanto a marcas nos verbos e nos nomes. Estudos da Lingua(gem). Vitória da Conquista, v.13, n.2, p.59-72, dez.2015.

LUCCHESI, Dante. Language in contact in Brazil and the genesis of creole languages. Journal of Ibero-Romance Creoles, $\mathrm{v}$. 9, n. 1, p. 334-357, 2019a.

Por que a crioulização aconteceu no Caribe e não aconteceu no Brasil? Condicionamentos sócio-históricos. Gragoatá, Niterói, v.24, n. 48, p. 227-255, jan.-abr. $2019 b$.

. Lingua e Sociedade Partidas: a polarização sociolinguística do Brasil. São Paulo: Contexto, 2015. 
O contato entre línguas e a origem do português brasileiro. In: GUGENBERGER, Eva; MONTEAGUDO, Henrique; REI-DOVAL, Gabriel. Contacto de linguas, hibrididade, cambio: contextos, procesos e consecuencias. Santiago de Compostela: Consello da Cultura Galega, 2013.

A deriva secular na formação do português brasileiro: uma visão crítica. In: LOBO, Tânia; CARNEIRO, Zenaide; SOLEDADE, Juliana; ALMEIDA, Ariadne; RIBEIRO, Silvana (orgs.). ROSAE: linguística histórica, história das linguas e outras histórias. Salvador: EDUFBA, 2012a. p. 249-274.

A diferenciação da língua portuguesa no Brasil e o contato entre língua. Estudos de linguística galega. 4, pp. 45-65, 2012b.

Ciência ou dogma? O caso do livro do MEC e o ensino de língua portuguesa no Brasil. Revista Letras, Curitiba, n. 83, p. 163 187, jan./jun. 2011.

. História do Contato entre Línguas no Brasil. In: LUCCHESI; Dante; BAXTER, Alan; RIBEIRO, Ilza (orgs.). $O$ Português Afro-Brasileiro. Salvador: Edufba, 2009. p. 41-73.

Aspectos gramaticais do português brasileiro afetados pelo contato entre línguas: uma visão de conjunto. In: RONCARATI, Cláudia; ABRAÇADO, Jussara (Org.). Português brasileiro II: contato linguístico, heterogeneidade e história. Niterói: EDUFF, 2008. p.366-390.

LUCCHESI, Dante; BAXTER, Alan. A transmissão Linguística Irregular. In: LUCCHESI; Dante; BAXTER, Alan; RIBEIRO, Ilza (orgs.). O Português Afro-Brasileiro. Salvador: Edufba, 2009. p. 101-124.

LUCCHESI; Dante; BAXTER, Alan; RIBEIRO, Ilza (orgs.). $O$ Português Afro-Brasileiro. Salvador: Edufba, 2009.

MARRETTO, Rodrigo Marins. A escravidão velada: senhores e escravos na formação da Vila de São João Batista de Nova Friburgo (1820-1850). Rio de Janeiro: Revan, 2018. 
MAYER, Jorge Miguel. A criação de Nova Friburgo. In: ARAÚJO, João Raimundo de; MAYER, Jorge Miguel. Teia serrana: formação histórica de Nova Friburgo. Rio de Janeiro: Ao Livro Técnico, 2003.

MCWHORTER, John. Language Interrupted. Oxford: Oxford University Press, 2007.

MILROY, Lesley; MILROY, James. Social network and social class: toward an integrated sociolinguistic model. Language in Society, Cambridge, n. 21, p. 1-26, 1992.

MOTA, Maria Antónia; MIGUEL, Matilde; at al. A concordância de p6 em português falado. Os traços pronominais e os traços de concordância. Papia, v. 1, n. 22, p. 161-188, 2012.

NARO, Anthony. The social and structural dimensions of a syntactic change. Language, v.57, n.1, p.63-98, 1981. Disponível em: https://www.jstor.org/stable/414287?seq=1. Acesso em: 04/01/2021.

NARO, Anthony; SCHERRE, Marta. Origens do português brasileiro. São Paulo: Parábola, 2007.

Mudança sem mudança: a concordância de número no português brasileiro.Scripta, Belo Horizonte, v. 9, n. 18, p. 107-129, $1^{\circ}$ sem. 2006.

NICOULIN, Martin. A Gênese de Nova Friburgo: emigração e colonização suíça no Brasil (1817-1827). Rio de Janeiro: Fundação Biblioteca Nacional, 1995.

OLIVEIRA, Victor Pereira de. Repensando o rural sob o prisma das urbanidades, em Nova Friburgo, RJ. Curitiba: CRV, 2011.

OUSHIRO, Lívia. Identidade na pluralidade: avaliação, produção e percepção linguística na cidade de São Paulo. 2015. 394f. Tese (Doutorado em Linguística) - Faculdade de Filosofia, Letras e Ciências Humanas, Universidade de São Paulo, São Paulo, 2015.

PAIVA, Maria da Conceição de. A variável gênero/sexo. In: MOLLICA, Maria Cecília; BRAGA, Maria Luiza. Introdução 
à Sociolinguística: o tratamento da variação. 3. ed. São Paulo: Contexto, 2007.

SCHERRE, Marta. Reanálise da Concordância Nominal em Português. 1988. 554f. Tese (Doutorado em Linguística) Faculdade de Letras, Universidade Federal do Rio de Janeiro, Rio de Janeiro, 1988.

TRUDGILL, Peter. Contact and Sociolinguistic Typology. In: HICKEY, Raymond (ed.). The Handbook of Language Contact. Chichester: Wiley-Blackwell, 2010. p. 299-319.

. Sociolinguistic typology and complexification. In: SAMPSON, Geoffrey; GIL, David; TRUDGILL, Peter (eds.). Language complexity as an evolving variable. Oxford: Oxford University Press, 2009. p. 97-108.

Contact and simplification: Historical baggage and directionality in linguistic change. Linguistic Typology, Berlim, v. 5, n. 2-3, p. 371-374, 2001.

VIEIRA, Silvia Rodrigues; BAZENGA, Aline. Patterns of third person plural verbal agreement. Journal of Portuguese Linguistics, Lisboa, v. 12, n. 2, p. 7-50, 2013.

VOTRE, Sebastião Josué. Relevância da variável escolaridade. In: MOLLICA, Maria Cecília; BRAGA, Maria Luiza. Introdução à Sociolinguística: o tratamento da variação. 3. ed. São Paulo: Contexto, 2007.

WEINREICH, Uriel; LABOV, William; HERZOG, Marvin. Fundamentos empíricos para uma teoria da mudança lingüística. São Paulo: Parábola, 2006[1968].

WINFORD, Donald. An introduction to Contact Linguistic. Oxford: Blackwell, 2003. 


\section{ABSTRACT}

\section{The Variation in Number Agreement in Nominal Phrase in Rural Portuguese in Mountain Region in Rio de Janeiro State: Drift or Contact?}

The article presents an apparent-time sociolinguistic analysis about the variation in number agreement in the Noun Phrase (NP) in the rural Portuguese of the mountain region of the State of Rio de Janeiro. We observed the application or not of the agreement rule in the NP as a whole, in what was called a syntagmatic or non-atomistic approach. The variation analysis was based on a sample of vernacular speech collected in the rural area of Nova Friburgo city, with 35 informants from two generations, distributed by both genres. Data collected in the speech sample were submitted to quantitative processing of multivariate calculations, using the GoldVarb program, to identify the social constraints of the variable phenomenon. We assumed that the variation in nominal number agreement is the result of a change induced by contact between languages that occurred in the past, considering the sociolinguistic history of Brazil as a whole and particularly the multilingualism present in the history of the region, which brought together Swiss, German and Portuguese settlers, as well as enslaved Brazilians and Africans. Therefore, the hypothesis that guided the whole analysis was that the mechanism of nominal agreement would have been eroded in the past due to linguistic contact and today it would be recomposing itself due to the linguistic leveling that characterizes popular Portuguese since the middle of the 20th century, in the context of sociolinguistic polarization of Brazil. And the empirical results proved that contact between languages acted strongly in the formation of popular varieties of Brazilian Portuguese mainly affecting grammatical mechanisms that have no information value.

Keywords: Nominal agreement. Linguistic variation. Rural Portuguese. Language contact. Drift. 


\section{Agradecimentos}

Agradecemos, pelo auxílio na organização dos dados aqui apresentados, às bolsistas, participantes de projetos indiretamente vinculados a esta pesquisa: Yasmim Abrahão Raposo (UFF/IFF-CNPq); Pollyana de Oliveira Moura Nogueira (IFF/CNPq); e Bárbara Emiliano Rangel (IFF-Faperj).

Jaqueline de Moraes Thurler Dália é Doutora em Estudos da Língua (UERJ, 2017), Professora de Língua Portuguesa do Instituto Federal Fluminense (IFF), Líder do NuPERF - Núcleo de Pesquisas e Estudos sobre as Ruralidades Fluminenses - IFF.

Dante Luccchesi é Doutor em Linguística (UFRJ, 2000), Professor Titular de Língua Portuguesa da Universidade Federal Fluminense (UFF), Bolsista de Produtividade em Pesquisa do CNPq, Nível 1-B (Proc.: 305053/2019-1). 